Research, Society and Development, v. 7, n. X, p. 01-X, eXX, 2018

ISSN 2525-3409 (CC BY 4.0)

\title{
Resíduos Sólidos Orgânicos: Uma Análise Cienciométrica Acerca da Utilização da Compostagem Para a Geração de Adubo
}

Organic Solid Waste: A Scientometric Analysis on the Use of Composting for Fertilizer Generation

Jonatas Teixeira Santos

Fundação Comunitária de Ensino Superior de Itabira, Brasil

E-mail: joh.8788@hotmail.com

Juliana Caroni Silva Guimarães

Fundação Comunitária de Ensino Superior de Itabira, Brasil

E-mail: julianacaroni@yahoo.com.br

Adélia Franco

Fundação Comunitária de Ensino Superior de Itabira, Brasil

E-mail: adelia.franco@yahoo.com.br

Juni Cordeiro

Fundação Comunitária de Ensino Superior de Itabira, Brasil

E-mail: juni.cordeiro@funcesi.br

Cibele Andrade de Alvarenga

Fundação Comunitária de Ensino Superior de Itabira, Brasil

E-mail: cibele.alvarenga@funcesi.br

Charles Ianne Ferreira dos Santos

Fundação Comunitária de Ensino Superior de Itabira, Brasil

E-mail: charles.ianne@ funcesi.br

Paulo Therezo

Fundação Comunitária de Ensino Superior de Itabira, Brasil

E-mail: paulo.therezo@funcesi.br

Recebido: 07/02/2018 - Aceito: 06/08/2018

\section{Resumo}

A compostagem consiste em transformar a matéria orgânica em composto utilizado como adubo, retornando os nutrientes para o solo. Esta pesquisa objetivou analisar a evolução espaço-temporal da publicação de artigos que abordam o uso da compostagem para produção de adubos. Foram utilizados 467 artigos obtidos por meio de palavras-chave na base de dados 
Web of Science publicados entre os anos de 1992 a 2017. Observou-se um aumento no número de publicações a partir de 2010. Os países que mais publicaram foram a Espanha, seguida pela Itália e Estados Unidos. As revistas com maior número de artigos foram a Environmental Sciences e a Soil Science; já as áreas de pesquisa mais citadas foram a Agricultura e Ecologia das Ciências Ambientais. Os macronutrientes mais citados foram o nitrogênio, fósforo e potássio; já dentre os micronutrientes podem ser salientados o zinco e o cobre. As culturas foram citadas em 47,5\% dos artigos analisados, podendo ser destacadas o milho o tomate e o trigo. O número de publicações aumentou durante os anos, mostrando a busca por alternativas sustentáveis, como a compostagem que produz composto rico em nutrientes e matéria orgânica.

Palavras-chave: Matéria orgânica; Fertilizante; Reaproveitamento de Resíduos.

\begin{abstract}
Composting consists of transforming the organic matter into compost used as fertilizer, returning the nutrients to the soil. This research aimed to analyze the space-time evolution of the publication of articles that discuss the use of composting for fertilizer production. A total of 467 articles were obtained using keywords in the Web of Science database published between 1992 and 2017. There was an increase in the number of publications from 2010. The most published countries were Spain, followed by Italy and the United States. The journals with the largest number of articles were Environmental Sciences and Soil Science; already the most cited research areas were Agriculture and Ecology of Environmental Sciences. The most frequently mentioned macronutrients were nitrogen, phosphorus and potassium; already among the micronutrients can be emphasized zinc and copper. Cultures were cited in $47.5 \%$ of the analyzed articles, with corn, tomato and wheat being highlighted. The number of publications has increased over the years, showing the search for sustainable alternatives such as composting that produces nutrient-rich compounds and organic matter.
\end{abstract}

Keywords: Organic matter; Fertilizer; Reuse of Waste.

\title{
1. Introdução
}

O volume de resíduos produzido pela população mundial aumentou consideravelmente nos últimos anos, contribuindo para o surgimento de vários desafios ambientais, tais como a redução e destinação final adequada desses materiais. De acordo com Saiani, Dourado e Toneto Júnior (2014), as maiores parcelas de resíduos são descartadas a céu aberto e em 
aterros controlados, o que agrava os riscos ambientais como contaminação do solo e das águas, emissão de gases poluentes e proliferação de vetores.

Destaca-se que, segundo a Norma Brasileira (NBR) 10.004 da Associação Brasileira de Normas Técnicas - ABNT (2004), os resíduos sólidos correspondem aos materiais sólidos ou semissólidos provenientes de atividades industrial, doméstica, hospitalar, comercial, agrícola e de serviços de varrição, incluindo também os lodos originados no sistema de tratamento de água.

Sabe-se que as atividades industriais são responsáveis pela geração significativa de resíduos sólidos, além de efluentes líquidos e gasosos contendo metais pesados, poluentes orgânicos, dentre outros, que podem desencadear a poluição quando lançados de forma inadequada no meio ambiente. Entretanto, as atividades agropecuárias (cultivo de animais, de alimentos, árvores) são as maiores geradoras de resíduos orgânicos estritamente sólidos (COOPER et al., 2010).

Um dos meios para minimizar o volume de substâncias dispostas no meio ambiente é representado pela compostagem, que consiste em uma técnica capaz de transformar a matéria orgânica de resíduos em um composto que pode ser utilizado como adubo, favorecendo assim, a reciclagem de nutrientes (PEREIRA NETO, 2007).

Destaca-se que o composto orgânico possui os elementos nitrogênio $(\mathrm{N})$, fósforo $(\mathrm{P})$, magnésio $(\mathrm{Mg})$ e enxofre $(\mathrm{S})$, classificados como macronutrientes por serem assimilados em maiores quantidades pelas plantas; e ferro $(\mathrm{Fe})$, zinco $(\mathrm{Zn})$, cobre $(\mathrm{Cu})$, manganês $(\mathrm{Mn})$, boro (B) e outros que são absorvidos em quantidades menores, sendo, por isso, denominados micronutrientes (BETTIOL; CAMARGO, 2006). Além disso, Pereira Neto (2007) destaca que o adubo produzido pelo processo de compostagem tem efeitos positivos nas propriedades físico-químicas do solo, tais como o aumento de sua produtividade, possuindo diversas aplicações como em hortas, recuperação de solos esgotados, fruticultura, entre outras.

Neste contexto, a compostagem corresponde a uma forma de atender a demanda do mercado agrícola, reduzindo o volume de fertilizantes sintéticos produzidos e utilizados nas culturas, e a necessidade ambiental, de forma a permitir a reciclagem de nutrientes e a demanda das plantas.

Dessa forma, o objetivo deste artigo é analisar a evolução espaço-temporal dos trabalhos científicos publicados e indexados no banco de dados Web of Science voltados para a reutilização, como fertilizante, de resíduos sólidos orgânicos, entre os anos de 1991 e 2017.

Uma grande parte dos resíduos produzidos pelo homem é de origem orgânica, ou seja, restos de alimentos, sobras de frutas e legumes, resíduos orgânicos industriais e 
agroindustriais, lodos orgânicos, podas, gramas e palhas. Uma forma eficiente para obter a biodegradação destes resíduos é por meio da compostagem, um processo biológico aeróbico capaz de transformar a matéria orgânica em material com propriedades que podem favorecer o solo e as plantas, denominado húmus (PEREIRA NETO, 2007).

A degradação ativa acontece por meio de uma população diversificada de bactérias e fungos (PEREIRA NETO, 2007); já a maturação ocorre quando as partículas que foram biodegradadas estão em estágio de humificação, deixando o composto com odor agradável (FERNANDES, 1999).

Ressalta-se que a degradação da matéria orgânica pode ser influenciada pela aeração, o pH, a estrutura e a umidade. A relação do carbono (C) e nitrogênio (N) é considerada o fator que melhor representa o equilíbrio dos substratos, pois os microrganismos necessitam de carbono como fonte de energia e nitrogênio para a síntese de proteínas (CASTILHOS JR, 2006). Conforme Pereira Neto (2007), no início a relação C/N situa-se entre 30 e 40: 1, sendo considerada ótima para a eficiência da compostagem. No final, quando o composto é maturado, a relação decresce para 10: 1 .

De acordo com Philippi Jr, Roméro e Bruna (2014), nas situações nas quais há abundância de carbono na massa, a relação $\mathrm{C} / \mathrm{N}$ é alta, assim, como consequência, o período de compostagem pode aumentar e a síntese celular será baixa devido à decadência de nitrogênio. Dessa forma, para que a relação $\mathrm{C} / \mathrm{N}$ se estabilize, é preciso adicionar material rico em nitrogênio como lodo de esgoto e legumes frescos.

Quando houver maior concentração de nitrogênio comparado com carbono, a relação $\mathrm{C} / \mathrm{N}$ será baixa, entretanto, o excesso de nitrogênio é eliminado do composto de forma praticamente natural, pela ação dos microrganismos por meio da volatização da amônia, deixando a relação C/N equilibrada novamente (PHILIPPI JR; ROMÉRO; BRUNA, 2014).

A temperatura também é um fator importante, principalmente no que diz respeito à rapidez do processo de biodegradação e à eliminação de patógenos (CASTILHOS JR, 2006). Segundo Philippi Jr. (2005), este processo é eficiente na redução de patógenos visto que, em uma das etapas da decomposição da matéria orgânica, a temperatura pode chegar a $70^{\circ} \mathrm{C}$. Contudo, Pereira Neto (2007) ressalta que temperaturas superiores a $65^{\circ} \mathrm{C}$ devem ser evitadas, pois causam a morte dos microrganismos degradadores da matéria orgânica.

Em geral, a técnica de compostagem é segmentada nas etapas mesofílica, termofílica e de maturação, que são muito distintas uma das outras. Segundo Fetti (2014), na primeira etapa, com duração de aproximadamente quinze dias, a temperatura não ultrapassa os $40^{\circ} \mathrm{C}$. Desse modo, em temperatura ambiente, a proliferação de microrganismos mesofílicos, 
principalmente as bactérias, contribuem incialmente para a degradação de compostos mais simples.

A fase subsequente é a termofílica, que acontece mediante o aumento da temperatura devido à dificuldade de dissipação do calor na matéria orgânica. Como consequência deste aumento da temperatura há uma vasta proliferação de microrganismos que degradam o composto (PEREIRA NETO, 2007).

Em relação a todas as fases da compostagem, a etapa termofílica é a mais prolongada, com duração de até dois meses. A degradação das moléculas mais complexas nesta etapa acontece pela ação de fungos e bactérias termofílicos, que permanecem vivos a temperaturas de $65^{\circ} \mathrm{C}$ a $70^{\circ} \mathrm{C}$. Ainda nessa etapa há um alto consumo de oxigênio devido à degradação da matéria orgânica e a eliminação de microrganismos patogênicos (FETTI, 2014).

A fase de maturação é a última etapa do processo e tem duração de um a dois meses. Devido à diminuição das atividades microbianas ocorre a queda do $\mathrm{pH}$ e da temperatura que retorna àquela do ambiente. Ao fim, a decomposição da matéria orgânica é transformada em composto orgânico (FETTI, 2014). Destaca-se ainda que a produção do húmus também está associada a uma série de reações enzimáticas complexas relacionadas particularmente com a condensação entre ligninas e proteínas (PEREIRA NETO, 2007).

A compostagem dos resíduos sólidos pode causar impactos ambientais negativos e transtornos sociais quando as técnicas utilizadas para cada fase do processo são mal executadas ou inexistentes. Os problemas mais frequentes durante a operação da compostagem são: odores, a proliferação de vetores e a produção de chorume (PEREIRA NETO, 2007).

Antes de implantar a compostagem, o principal passo para evitar os possíveis impactos negativos decorrentes do seu processo é a escolha da localização adequada, evitando áreas próximas a um curso d'água, uma vez que nestes locais podem ocorrer a erosão e o transporte dos resíduos pela chuva (FERNANDES, 1999).

O adubo orgânico é um produto estável oriundo da transformação da matéria orgânica por meio de processo aeróbico. Quanto este adubo atinge concentrações específicas de nutrientes exigidas pela legislação brasileira, o composto é denominado fertilizante orgânico (PEREIRA NETO, 2007).

Segundo Massukato (2016), apesar de não apresentar altos teores de nutrientes o composto orgânico resultante da compostagem contém NPK (Nitrogênio, Fósforo e Potássio), cálcio, magnésio e enxofre, que são nutrientes essenciais para as plantas, além disso, o adubo melhora as qualidades físicas solo, tais como o aumento da sua permeabilidade, diminuindo a 
possibilidade de erosão; melhora a retenção de umidade e a estrutura do solo em virtude dos movimentos da água, ar e raízes das plantas.

Além disso, conforme Pereira Neto (2007), o adubo favorece o aumento da produtividade vegetal, pois disponibiliza nutrientes para o desenvolvimento das plantas, podendo ser aplicado em diversas atividades como na produção de horticultura, fruticultura e produção de grãos, possuindo ainda aproveitamento em atividades de reflorestamento, projetos paisagísticos e jardins.

Dessa forma, a integração do adubo orgânico com o solo melhora as suas propriedades químicas, físicas e biológicas, por meio do fornecimento de nutrientes, favorecendo a estrutura do solo com mais aeração e permeabilidade, permitindo também, a reciclagem de nutrientes para o meio de forma natural.

\section{Metodologia}

Nesta pesquisa foram utilizadas as abordagens quantitativa e qualitativa. Destaca-se que a abordagem quantitativa considera que tudo pode ser quantificável, o que significa traduzir em números opiniões e informações para classificá-las e analisá-las, fazendo-se necessário o uso de métodos e técnicas estatísticas (MARCONI; LAKATOS, 2003). Por outro lado, a abordagem qualitativa considera que há uma relação dinâmica entre o mundo real e o sujeito, assim, a interpretação dos fenômenos e a atribuição de significados são básicas no processo de pesquisa qualitativa (MORESI, 2003). A análise qualitativa foi utilizada nesta pesquisa para na tradução dos artigos coletados e sua interpretação.

Para esta investigação foi utilizada a pesquisa descritiva que, de acordo com Vergara (2011), é classificada também como pesquisa de opinião, de modo que, descreve particularidades de fenômenos ou de determinada população.

O método de pesquisa utilizado para a elaboração do trabalho foi a ciênciometria, que consiste em um método de pesquisa que utiliza critérios qualitativos para compreender diversos fenômenos científicos, desempenhando um importante papel na estruturação de políticas científicas (CHAPULA, 1998). Ressalta-se que esse mesmo método de pesquisa foi utilizado na Fundação Comunitária de Ensino Superior (Funcesi) nos trabalhos de Ferreira (2016), Silva (2016), Soares (2016), Rodrigues (2017) e Guimarães (2017).

Segundo Vergara (2011), o universo é definido como população, isto é, um conjunto de elementos, sejam eles pessoas, empresas ou produtos, de modo que todas as suas características serão destinadas ao estudo. Assim, o universo deste trabalho foi composto por 
artigos indexados no banco de dados Web of Science, que abordavam o tema "reaproveitamento de resíduos sólidos orgânicos utilizando o método da compostagem para a geração de adubo", publicados entre 1994 e 2017. A seleção deste conjunto de dados se explica pela diversidade dos artigos pertinentes à área de ciências naturais, fornecendo dados de artigos publicados em âmbito internacional, a partir do ano de 1954.

Para a delimitação do universo foi realizada no dia 20 de janeiro de 2018 uma busca de artigos na base de dados Web of Science a partir de palavras chaves em inglês, tais como "composting" (compostagem) AND "solid waste" (resíduos sólidos) AND "fertilizers" (fertilizantes). A busca foi feita em inglês, pois este é o idioma predominante no meio científico, o que possibilitou encontrar 467 artigos relacionados ao reaproveitamento de resíduos sólidos orgânicos utilizando o método da compostagem para a geração de adubo no meio agrícola.

Assim, a amostra deste estudo correspondeu aos 467 artigos científicos obtidos por meio de pesquisa utilizando palavras-chave na base de dados da Web of Science. Desta forma, a amostra trata-se de um censo, uma vez que todos os elementos no universo foram utilizados na análise de dados (GIL, 2002).

A coleta dos dados deste estudo ocorreu por meio de pesquisa documental a partir das planilhas geradas pela pesquisa de palavras-chave no banco de dados Web of Science. De acordo com Ludwig (2012) a análise documental é representada como um recurso que permite revelar informações em documentos a partir de questões ou hipóteses já delimitadas.

O tratamento de dados desta pesquisa empregou a estatística descritiva e inferencial. De acordo com Marconi e Lakatos (2003), o objetivo da estatística descritiva é o de representar, de forma concisa, sintética e compreensível, a informação contida em um conjunto de dados. Esta tarefa, que adquire grande importância quando o volume de dados é grande, concretiza-se na elaboração de tabelas e de gráficos, e no cálculo de medidas ou indicadores que representam convenientemente a informação contida nos dados. Por sua vez, de acordo com Correa (2003), a estatística inferencial possibilita o pesquisador associar teorias e práticas, possibilitando a obtenção de maior confiabilidade nos resultados obtidos por meio da análise das amostras.

Assim, a estatística descritiva foi utilizada nesta pesquisa com o intuito de descrever e quantificar as informações publicadas sobre o tema "lodo de esgoto na agricultura", possibilitando examinar e comparar os dados obtidos, já a estatística inferencial foi empregada para averiguar se ocorreu um aumento relevante do número de publicações de 
artigos entre os anos de 1994 e 2017 por meio de regressão polinomial ao nível de 5\% de significância.

De acordo com Vergara (2011) toda pesquisa é suscetível a limitações. Assim, este trabalho apresentou como limitações o método de pesquisa utilizado, uma vez que foi utilizado somente o banco de dados Web of Science. Outro fator limitante foi a busca dos artigos por meio de palavras-chave escolhidas pelo pesquisador, sendo possível ter acesso ter somente aos artigos pertinentes às palavras selecionadas.

\section{Resultados e Discussão}

Por meio da análise cienciométrica foi possível observar um aumento no número de publicações de artigos que abordam a utilização da compostagem como adubo entre os anos de 1992 a 2017, conforme ilustra o Gráfico 1. Faz-se importante salientar que estes anos foram selecionados devido a escolha das palavras-chave utilizadas para realizar a pesquisa e à disponibilidade de artigos no banco de dados utilizado.

\section{Gráfico 1- Evolução da publicação de artigos sobre o uso da compostagem como adubo entre os anos de 1992 a 2017}

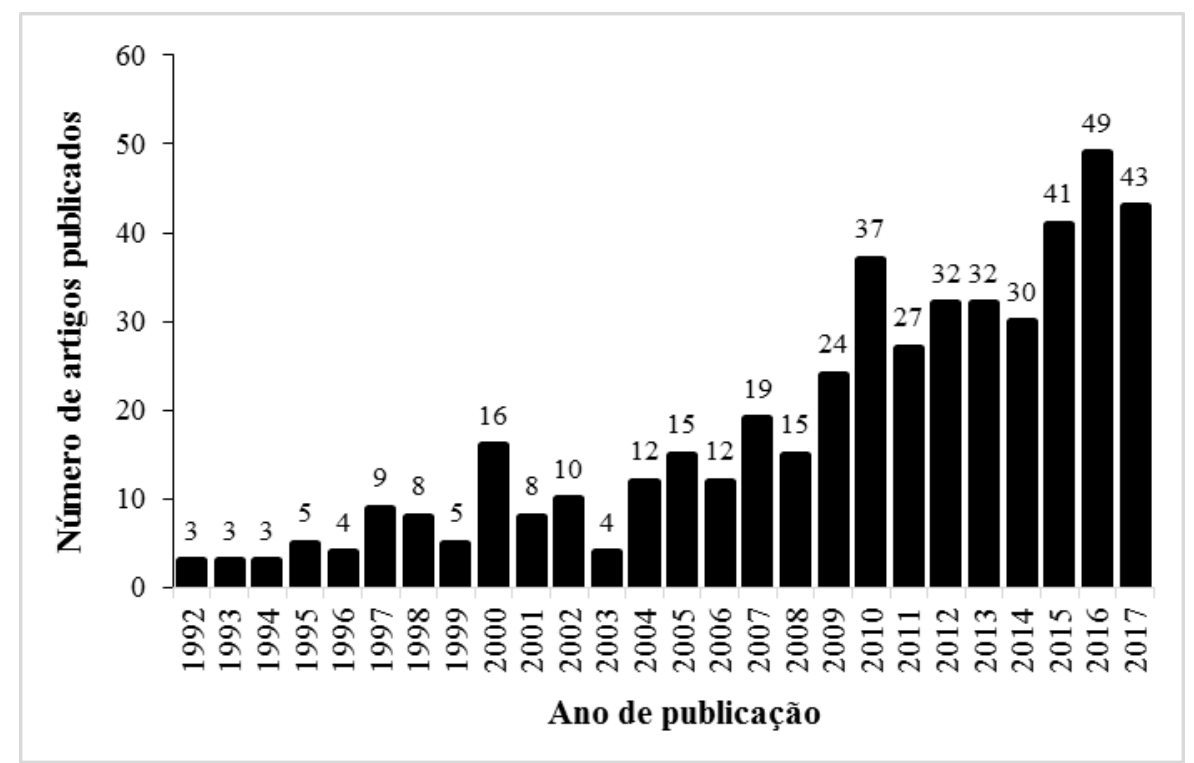

Fonte: Dados da pesquisa.

De acordo com os dados observados no Gráfico 1, é possível constatar um aumento inconstante do número de publicações entre as décadas. Assim, entre os anos de 1990 a 1999 foram publicados $8,6 \%$ dos artigos, entre 2000 a 2009 houve $29 \%$ de publicações e $62,4 \%$ 
entre 2010 e 2017. Observa-se que o ano de 2016 obteve o maior percentual de publicações, com 49 artigos publicados, correspondendo a 10,5\% do total de publicações.

O aumento no número de publicações a partir do ano de 2010 pode ser justificado devido aos encontros mundiais sobre compostagem organizados pela Associação Interamericana de Engenharia Sanitária e Ambiental (AIDIS), desde 2010. Destaca-se que esses encontros incluem representantes da Áustria, China, Estados Unidos, entre outros, objetivando a promoção da conscientização acerca dos problemas ambientais, além de disseminar soluções eficientes e sustentáveis para os problemas contemporâneos, obedecendo as legislações vigentes de cada país (REVISTA DAE, 2016).

Considerando a hipótese de que ocorreu um aumento no número de artigos publicados após a proibição acerca do lançamento do lodo de esgoto nos oceanos foi investigada por meio da regressão polinomial o número de artigos publicados e o ano de publicação. Verificou-se uma relação estatisticamente significativa $\left(y=0,0738 x^{2}-294,09 x+293071 ; R^{2}\right.$ $=0,9118 ; \mathrm{p}<0,01)$, indicando que houve um aumento exponencial no número de artigos publicados, principalmente após o ano de 2010 (Graf. 2).

Gráfico 2 - Número de artigos publicados por ano, entre os anos de 1992 e 2017.

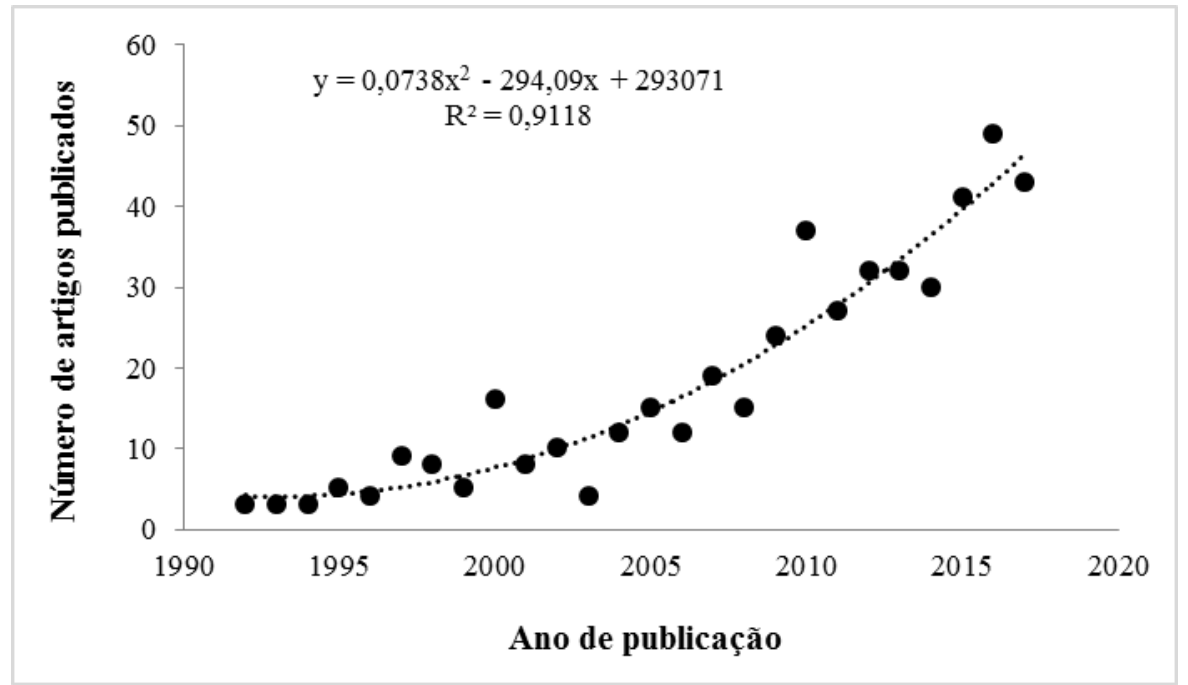

Fonte: Dados da pesquisa.

Assim, o encontro realizado pela AIDIS em 2010, pode ter contribuído para a promoção da conscientização ambiental em diversos países, além da busca pelo desenvolvimento de soluções eficientes para o descarte sustentável dos resíduos sólidos, favorecendo assim, o aumento no número de estudos e publicações relacionados ao tema.

4.1 Países que mais publicaram sobre a utilização de compostagem como adubo 
Foram analisados 467 artigos, correspondendo a 54 países, dentre os quais a Itália foi o país que mais publicou artigos, destacando-se com o percentual de 15,2\%. A Espanha e os Estados Unidos publicaram 13,7\% cada um, seguidos pelo Canadá e China que publicaram 7,5\% cada, enquanto o Brasil obteve o percentual de 2,6\% de artigos publicados. Por sua vez, a expressão "outros países" representa os países que alcançaram menos de $2 \%$ de publicações (Gráf. 3).

\section{Gráfico 3 - Porcentagem de publicação por país entre os anos de 1992 a 2017}

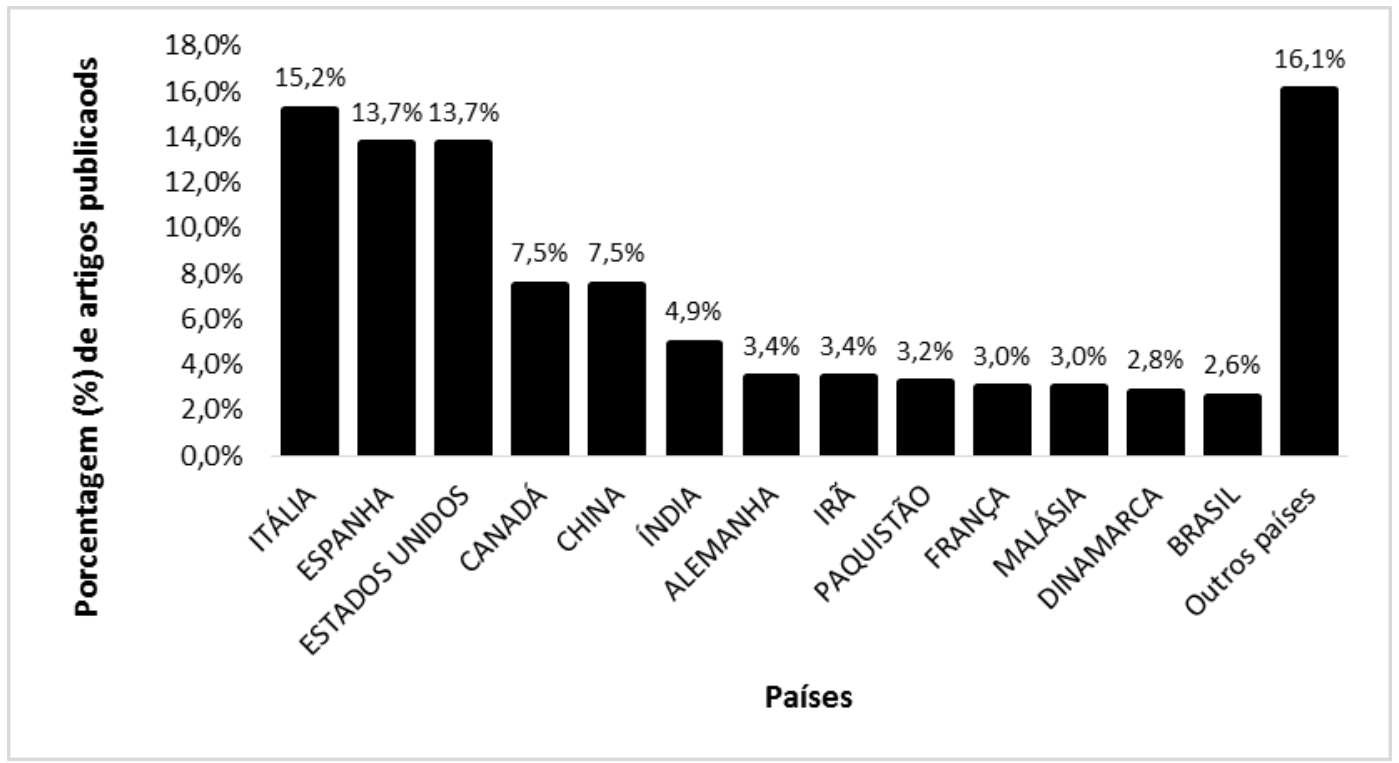

Fonte: Dados da pesquisa.

O maior percentual de publicação de artigos relacionados ao uso da compostagem para gerar adubos, atribuídos à Itália $(15,2 \%)$ pode estar associado à implantação de uma usina de compostagem na cidade de Salerno, em 2011, que se tornou referência na Europa. Neste sentido, salienta-se que no ano de 2013, a União Europeia reconheceu essa usina como um dos sistemas mais eficientes no reaproveitamento de resíduos orgânicos do continente, o que acelerou o crescimento do processo de compostagem na Itália (GALEFFI, 2013).

O percentual atingido pelos EUA $(13,7 \%)$ pode ser justificado pelo amplo investimento em pesquisas e desenvolvimento realizado por este país (ERICKSON, 2002). Já a Espanha representa um exemplo bem-sucedido de coleta seletiva e compostagem. Em 1997, foi aprovado um sistema de gestão de resíduos municipais e foi construída uma central de compostagem na Área Metropolitana de Barcelona. Assim, após a coleta seletiva da fração orgânica, os resíduos são transportados para a central de compostagem e após sua maturação, 
o composto é encaminhado para a fase de afinação e posteriormente vendido em diferentes granulometrias (COMISSÃO EUROEIA, 2000).

Ainda segundo a Comissão Europeia (2000), a maior parte dos compostos é aplicada em jardins privados e em pomares e olivais por pequenos agricultores, além disso, o composto também já foi utilizado para a recuperação e arborização de aterros e estradas.

Atualmente, na Espanha $31 \%$ de seus resíduos são destinados à compostagem, e 58\% dos resíduos são destinados a aterros, sendo que este último ainda está distante da média da União Europeia de 28\% (PARLAMENTO EUROPEU, 2017). Neste sentido, a Comissão Europeia propõe que $70 \%$ sejam encaminhados para a reciclagem e 5\% para os aterros, e por isso, a Espanha deve intensificar seus esforços para atingir 50\% de reciclagem dos resíduos até 2030, o que pode justificar o volume de estudos publicados por este país (REVISTA AMBIENTE PARA OS EUROPEUS, 2014).

Além disso, os países europeus (Itália, Espanha, Alemanha, França, Dinamarca), juntos, publicaram 38,1\% dos artigos, o que pode estar associado à existência de normas e limitações rígidas impostas pela União Europeia quanto ao uso de adubos orgânicos e agrotóxicos na agricultura, com o intuito de proteger o meio ambiente e a saúde pública (UNIÃO EUROPEIA, 2002).

O Brasil alcançou 2,6\% de total de artigos publicados entre os anos de 1992 a 2017, as pesquisas foram desenvolvidas na Empresa Brasileira de Pesquisa Agropecuária em Brasília, Universidade Federal de Lavras (MG), Centro de Pesquisas Florestais e Universidade Federal de Santa Maria (RS) e na Sociedade Brasileira de Ciência do Solo em Viçosa (MG).

Neste sentido, destaca-se que no Brasil, a Lei no 12305/2010 dispõe sobre Política Nacional dos Resíduos Sólidos (PNRS), incluindo os resíduos orgânicos. Um dos principais instrumentos da PNRS é o Plano Nacional de Resíduos Sólidos, que indica formas de estímulo à compostagem, como a implantação de unidades de compostagem, em conjunto com a coleta seletiva dos resíduos e o aproveitamento da capacidade de usinas de compostagem já instaladas (BRASIL, 2010).

Além disso, a PNRS em seu art. 33, afirma que é responsabilidade do titular dos serviços públicos de limpeza urbana, a adoção de procedimentos para reaproveitar os resíduos reutilizáveis e recicláveis, além de dar a disposição de forma ambientalmente adequada aos rejeitos. Por sua vez, o art. 25 declara que é dever do poder público, empresas e da população a execução de atividades para garantir de forma eficiente a observância da Política Nacional de Resíduos Sólidos (BRASIL, 2010). 
Estima-se que cerca de $60 \%$ dos resíduos urbanos do Brasil são de origem orgânica, ou seja, restos de alimentos, frutas, legumes, podas, que por meio da compostagem, tornam-se excelente fonte de nutrientes para as plantas (OLIVEIRA; AQUINO; CASTRO NETO, 2005). Todavia, apesar do potencial para a produção de adubo por meio da compostagem, segundo dados do Instituto Brasileiro de Geografia e Estatística - IBGE (2010) grande parte destes resíduos ainda são destinados aos lixões, apesar da Política Nacional do Meio Ambiente (Lei $n^{\circ}$ 6.938/1981) já ter advertido sobre os impactos negativos desta prática (BRASIL, 1981).

De acordo com o Compromisso Empresarial para Reciclagem (CEMPRE) em 2010, ano em que a PNRS foi instituída, 87\% dos resíduos foram dispostos em aterros ou lixões, e $13 \%$ foram reciclados ou compostados, e em 2015, apenas 5\%, dos resíduos orgânicos gerados no país foram reciclados ou compostados (CEMPRE, 2015). De acordo com a Abrelpe (2016), devido a ausência de iniciativas consolidadas para aproveitamento e recuperação da fração orgânica dos resíduos, aproximadamente 71,34 milhões de toneladas desses são encaminhados para o aterro sanitário, e 12,4 milhões de toneladas ainda são encaminhados a lixões.

Além disso, os artigos com o tema relacionado ao uso da compostagem como adubo foram publicados em 37 revistas científicas distintas, conforme ilustrado no Gráfico 4. A revista com o maior número de publicações foi a Environmental Sciences com $40 \%$ das publicações, seguida da Soil Science com 23\% e da Engineering Environmental com 16\%. As revistas Agronomy e Ecology publicaram respectivamente $14 \%$ e $11 \%$. As revistas Plant Sciences, Agriculture Multidisciplinary, Biotechnology Applied Microbiology, Horticulture, Energy Fuels, Agricultural Engineering, Green Sustainable Science Technology, publicaram entre 5 e $10 \%$ dos artigos. A categoria "outras revistas" foi inserida no gráfico para representar as revistas que tiveram menos de $5 \%$ de publicações.

\section{Gráfico 4 - Porcentagem de artigos publicados por revistas científicas entre os anos} de 1991 a 2017 


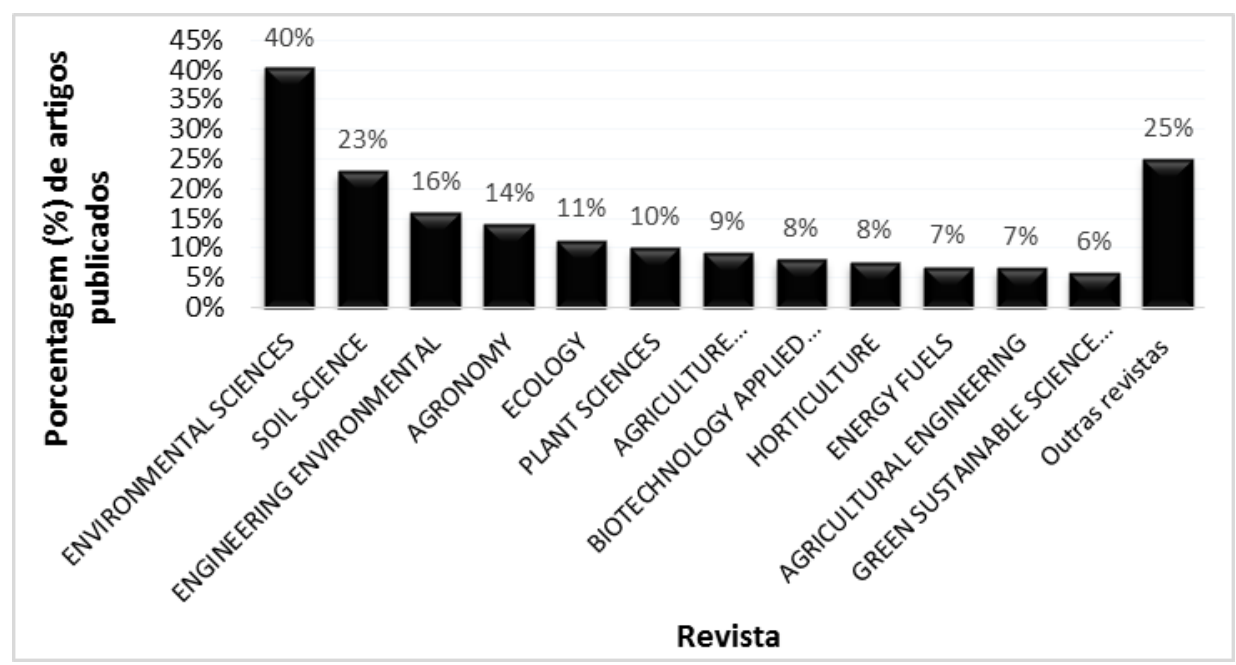

Fonte: Dados da pesquisa.

Destaca-se que a revista Environmental Sciences, responsável pela publicação de $40 \%$ dos artigos estudados, é patrocinada pelo Centro de Pesquisa de Ciências Ambientais da Academia Chinesa de Ciências, sendo publicada conjuntamente pela Elsevier e pela Science Press. De maneira geral, esta revista visa promover a comunicação interdisciplinar e promover a compreensão de questões ambientais significativas em diversas áreas, tais como ambiente aquático, ambiente atmosférico, biomonitoramento e biomarcadores contaminantes emergentes, análise e métodos ambientais, biologia ambiental química ambiental, catálise ambiental e nanomateriais, saúde ambiental e toxicologia, microbiologia ambiental, nanotecnologia ambiental, aconselhamento e gestão ambiental e ambiente terrestre (JOURNAL OF ENVIRONMENTAL SCIENCES, 2018).

4.2 Áreas de pesquisa com maior número de artigos publicados sobre o uso da compostagem para produção de adubo

Dentre as áreas que mais publicaram artigos, destacam-se a Agricultura e Ecologia das Ciências Ambientais, com 51,4\% e 47,5\% respectivamente, conforme ilustrado no Gráfico 5. A categoria "outras" foi inserida para classificar as áreas que tiveram menos de 5\% de artigos publicados. 
Research, Society and Development, v. 7, n. X, p. 01-X, eXX, 2018

ISSN 2525-3409 (CC BY 4.0)

Gráfico 5 - Áreas de pesquisas que mais publicaram artigos sobre a utilização de compostagem como adubo entre os anos de 1992 a 2017

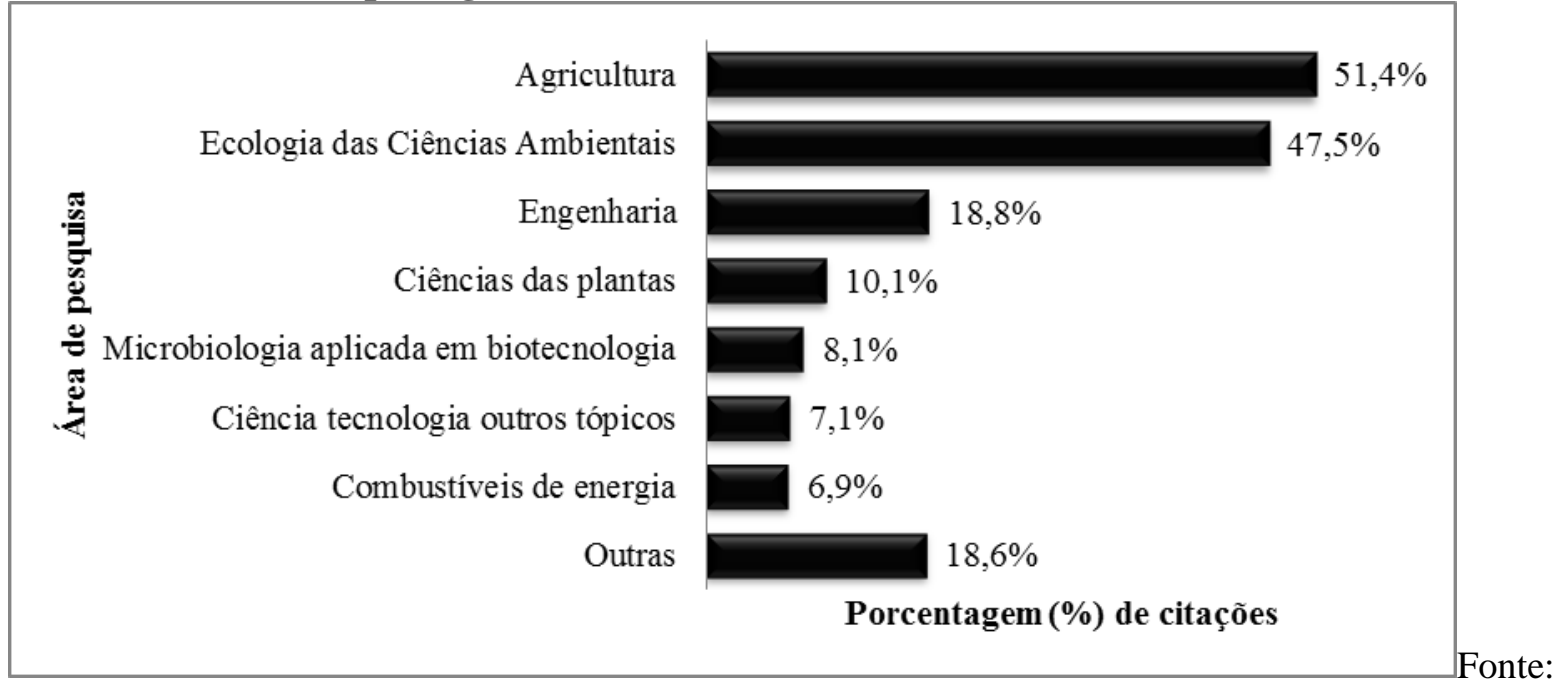

Dados da pesquisa.

Neste contexto, o uso da compostagem para a produção de adubo mostra-se um tema interdisciplinar, uma vez que revistas de diversas áreas de pesquisa, tais como agricultura, engenharia, combustíveis, entre outras, mostram interesse na publicação de artigos relacionados ao tema, o que pode estar relacionado às propriedades benéficas quanto ao fornecimento de nutrientes ao solo, produção de matéria-prima a partir do composto e até mesmo de outras fontes de combustíveis.

4.3 Nutrientes mais citados nos artigos publicados entre os anos de 1992 a 2017

Considerando os 467 artigos estudados, 55,2\% destes citaram os nutrientes presentes no adubo proveniente da compostagem. Salienta-se que alguns artigos mencionaram mais de um nutriente, dessa forma, foram observadas 515 citações, dentre as quais, 33 foram referentes à palavra "nutrientes". O nitrogênio $(\mathrm{N})$, fósforo $(\mathrm{P})$ e potássio $(\mathrm{K})$, obtiveram respectivamente $37,8 \%, 27,2 \%$ e 18,5\% de citações, conforme ilustrado no Gráfico 6.

Gráfico 6 - Nutrientes com maior número de citações $(\mathbf{n = 5 1 5 )}$ nos artigos selecionados do banco de dados Web of Science entre os anos de 1992 a 2017 


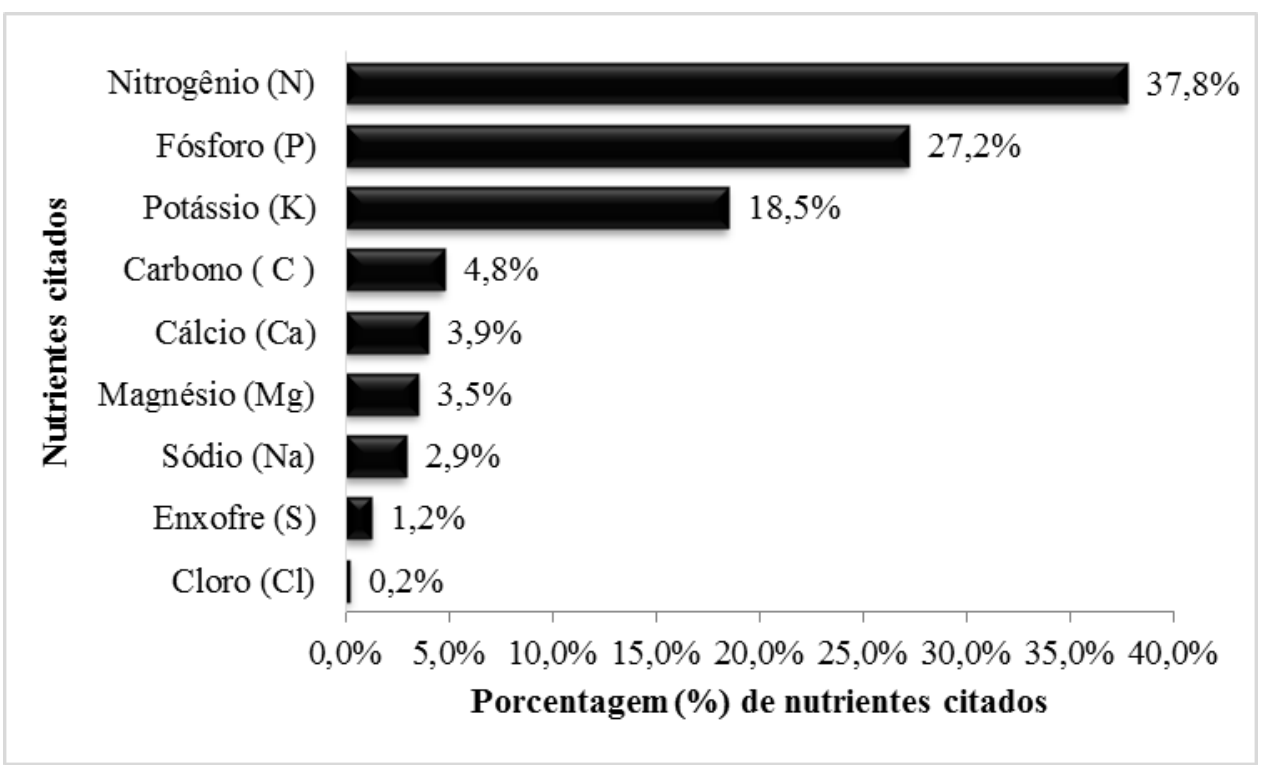

Fonte: Dados da pesquisa.

O número de citações acerca do carbono e do nitrogênio pode estar relacionado com o fato de serem nutrientes fundamentais para o crescimento bacteriano no processo de compostagem, visto que o carbono é a principal fonte de energia, enquanto o nitrogênio é necessário para a síntese celular (CASTILHOS JR, 2006).

Além disso, o nitrogênio desempenha um papel importante no desenvolvimento das plantas, pois compõe todas as proteínas, incluindo as enzimas, que controlam os processos biológicos. Já o fósforo é necessário em quantidades particularmente grandes nas extremidades da raiz, além disso, favorece o processo da fotossíntese, fixação de nitrogênio e no processo de maturação das plantas (BRADY; WEIL, 2013). Ainda segundo esses autores, o potássio atua no controle do processo osmótico das células das plantas, favorecendo a absorção de água pelas raízes, reduzindo assim as perdas pelos estômatos.

As plantas deficientes em enxofre tendem a ter baixo teor de açúcar em sua seiva, mas alta concentração de nitrato, tornando-as esguias e amareladas. O cálcio é o principal componente das paredes celulares, e também atua na divisão celular, permeabilidade da membrana e ativação de enzimas (BRADY; WEIL, 2013).

Ainda segundo Brady e Weil (2013), as plantas normalmente absorvem quantidades de magnésio equivalentes ou inferiores às de cálcio. A deficiência deste nutriente nas plantas causa um aparente envelhecimento e folhas amareladas, assemelhando-se aos sintomas de falta de oxigênio em solos encharcados. Segundo Andreoli, Von Sperling e Fernandes (2014) mesmo as baixas concentrações de $\mathrm{Ca}$ e $\mathrm{Mg}$ nos compostos, são suficientes para suprir a necessidade de um grande número de plantas. 
Salienta-se que elementos como zinco $(\mathrm{Zn})$, cobre $(\mathrm{Cu})$, arsênio (As), cobalto $(\mathrm{Co})$, cromo $(\mathrm{Cr})$, selênio $(\mathrm{Se})$ e ferro $(\mathrm{Fe})$, em pequenas concentrações são classificados como micronutrientes, possuindo um papel importante para o desenvolvimento das plantas (COSCIONE; NIGUEIRA; PIRES, 2010). Entretanto, em elevadas concentrações, podem ser classificados como elementos-traço e apresentam o risco de se acumular na cadeia alimentar, podendo também ser lixiviados, contaminando os cursos d'água (MOREIRA; SIQUEIRA, 2006).

Assim, com relação aos micronutrientes, 274 artigos fizeram referência aos elementos totalizando 308 citações. As substâncias mais citadas foram o zinco (Zn) com $20 \%$ de citações, o cobre $(\mathrm{Cu})$ com $19 \%$ e o chumbo $(\mathrm{Pb})$ com 14\%. O cádmio $(\mathrm{Cd})$, níquel $(\mathrm{Ni})$, cromo $(\mathrm{Cr})$ e magnésio $(\mathrm{Mn})$ obtiveram entre 5 e $10 \%$ de citações, já o ferro $(\mathrm{Fe})$, mercúrio ( $\mathrm{Hg}$ ), arsênio (As) e cobalto (Co) foram citados entre 0 e 5\%. O grupo "outras substâncias" representa os elementos que obtiveram menos de $1 \%$ de citações, tais como selênio, alumínio, molibdênio e boro, conforme ilustrado na Tabela 1.

Tabela 1 - Principais substâncias inorgânicas citadas $(n=308)$ nos artigos publicados entre os anos de 1992 a 2017

\begin{tabular}{ccc}
\hline Substâncias inorgânicas & Frequência & $(\%)$ \\
\hline $\mathrm{Zn}$ & 62 & $20 \%$ \\
$\mathrm{Cu}$ & 59 & $19 \%$ \\
$\mathrm{~Pb}$ & 43 & $14 \%$ \\
$\mathrm{Cd}$ & 40 & $13 \%$ \\
$\mathrm{Ni}$ & 29 & $9 \%$ \\
$\mathrm{Cr}$ & 20 & $6 \%$ \\
$\mathrm{Mn}$ & 19 & $6 \%$ \\
$\mathrm{Fe}$ & 12 & $4 \%$ \\
$\mathrm{Hg}$ & 7 & $2 \%$ \\
$\mathrm{As}$ & 5 & $2 \%$ \\
$\mathrm{Co}$ & 5 & $2 \%$ \\
Outras substâncias & 7 & $2 \%$ \\
\hline Total & 308 & $100 \%$ \\
\hline
\end{tabular}

Fonte: Dados da pesquisa. 
O número de citações acerca das substâncias inorgânicas pode ser justificado pela preocupação acerca da toxicidade provocada por estes elementos, considerada maior do que as fontes orgânicas e radioativas (BRADY; WEIL, 2013). Ainda segundo esses autores, os elementos com maior potencial de contaminação e tóxicos em qualquer concentração ao homem e outros animais são: mercúrio, cádmio, arsênio, chumbo, níquel, cobre, zinco, cromo, molibdênio, manganês, selênio, boro e flúor, uma vez que não desempenham nenhuma função no metabolismo. Entretanto, para o desenvolvimento das plantas, em pequenas concentrações elementos como cobalto, cobre, ferro, magnésio, manganês e zinco desempenham função essencial (BETTIOL; CAMARGO, 2006).

Andreoli, Von Sperling e Fernandes (2014) consideram o zinco um micronutriente essencial, absorvido pelas plantas instantaneamente, contudo, o número de citações acerca deste elemento pode estar relacionado com sua presença nos adubos orgânicos e sua capacidade de se misturar com outros metais, potencializando seus efeitos tóxicos.

Além das substâncias citadas outros 33 artigos salientaram a presença de elementostraço nos compostos sem identificá-los, uma vez que estes representam um fator limitante para a aplicação do adubo no solo, devido aos riscos de lixiviação e acúmulo na cadeia alimentar (TSUTIYA et al., 2002).

Neste sentido, a aplicação do adubo no solo mostra-se uma das formas mais sustentáveis de destinação dos resíduos, pois fornece micro e macronutrientes para as plantas, além de permitir a reciclagem destes elementos. Entretanto, alguns adubos, principalmente se oriundos de resíduos industriais, podem conter elementos traços que tendem a se acumular nas culturas e, consequentemente, na cadeia alimentar, por isso, a aplicação do composto no solo deve atender os requisitos das leis vigentes e ser constantemente monitorado.

4.4 Principais culturas citadas nos artigos publicados entre os anos de 1992 a 2017

Com relação ao uso da compostagem para transformar resíduos em adubo orgânico, 282 artigos mencionaram as culturas nas quais o adubo foi aplicado, totalizando 47,5\% $(n=467)$ dos artigos. É importante destacar que alguns artigos citaram mais de uma cultura, totalizando 363 citações.

Entre as culturas mais citadas destacam-se o milho (9\%), o tomate (7\%) e o trigo (6\%). No Gráfico 7 observa-se que o arroz e avinha obtiveram 4\% de citações; azevém, alface, batata e cevada $3 \%$; enquanto grama, beterraba, pepino e pimenta alcançaram $2 \%$ das 
citações. O grupo "outras categorias" representa as culturas que alcançaram menos de $1 \%$ de citações e alcançaram juntos 50\% ( $\mathrm{n}=363)$.

\section{Gráfico 7 - Principais culturas citadas nos artigos publicados entre os anos de 1992 a 2017}

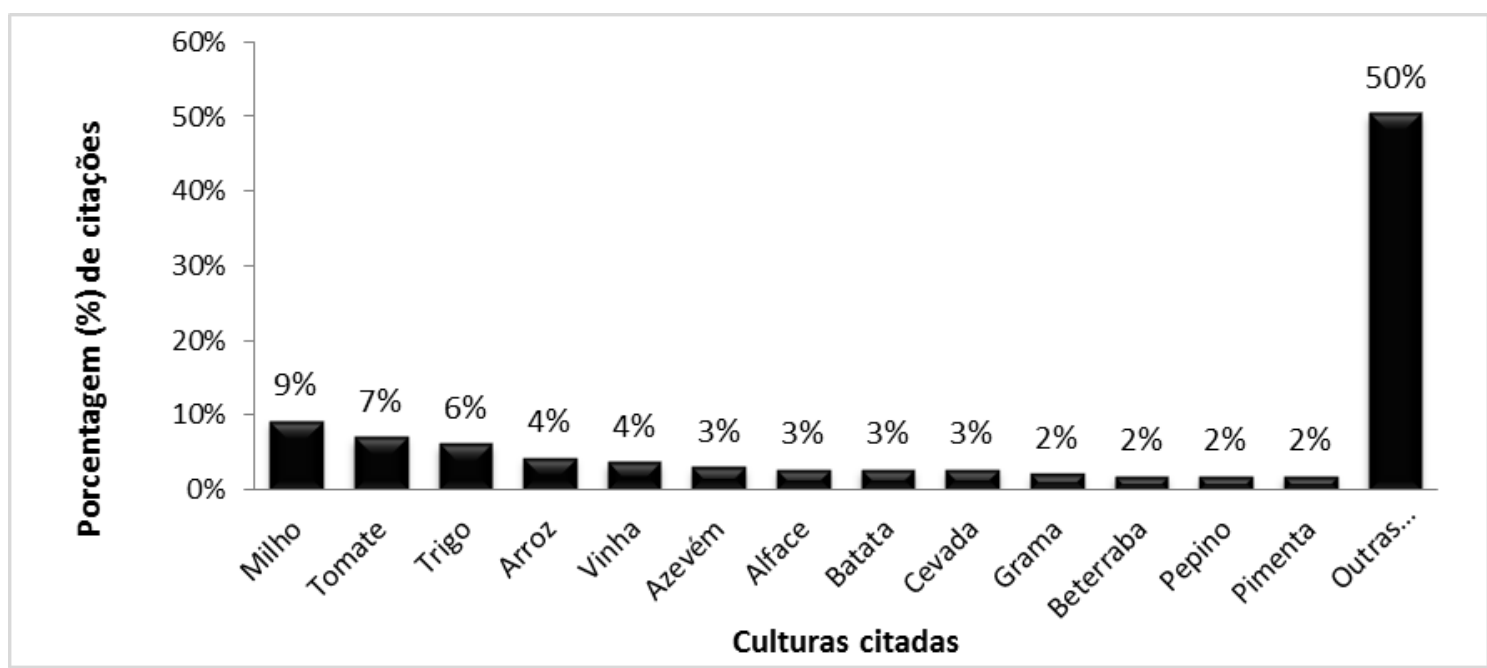

Fonte: Dados da pesquisa.

Segundo Barros e Calado (2005), cereais como o milho e o trigo possuem uma extensa capacidade de se adaptarem a diversos climas e regiões, além disso, são as culturas mais cultivadas em âmbito internacional. Assim, o maior número de citações acerca do milho e do trigo pode estar relacionado às facilidades de adaptabilidade às diversas condições climáticas e regiões.

Em relação ao tomate, Silva et al. (2006) afirmam que a hortaliça é uma das culturas mais exigentes em termos nutricionais e de adubação, pois a eficiência de absorção de nutrientes pelo tomateiro é baixa. Além disso, segundo Souza (2010), o tomate é uma cultura vulnerável a um grande número de doenças e pragas, e por isso, seu cultivo orgânico exige maiores cuidados com relação a outras culturas mais resistentes.

De acordo com Filgueira (2000), as hortaliças exibem resultados satisfatórios em sua produtividade com a adubação orgânica, uma vez que, especialmente em solos pobres em matéria orgânica, o composto traz benefícios aos tomateiros que possuem raízes delicadas e exigentes quanto às características físicas do solo. Neste sentindo, de acordo com Souza (2010), considerando as características desta hortaliça, é possível medir os níveis de rendimento e qualidade do composto utilizado para adubação.

Nota-se, dessa forma, que o adubo produzido pela compostagem é um material rico em matéria orgânica e nutrientes, podendo ainda favorecer as propriedades físico-químicas do 
solo. Entretanto, cada cultura exige teores de nutrientes distintos e por isso o adubo deve ser utilizado de acordo com as especificações no Ministério da Agricultura, Pecuária e Abastecimento.

\section{Considerações finais}

A compostagem é um processo biológico em que os microrganismos aeróbios transformam a fração orgânica dos resíduos sólidos em um composto rico em matéria orgânica e nutrientes denominado húmus, que pode ser utilizado como adubo e condicionador do solo. Este processo representa uma forma sustentável de descarte do lixo, pois permite a reciclagem de nutrientes no solo e melhora as propriedades físicas químicas e biológicas deste, além de diminuir o volume de resíduos dispostos em aterros, aumentando, assim, sua vida útil.

Neste sentido, tendo como principal objetivo analisar a evolução espaço-temporal dos artigos que abordam o uso da compostagem para produção de adubo, indexados no banco de dados Web of Science, foi possível observar um aumento no número de publicações ao longo das décadas entre os anos de 1992 a 2017.

Além disso, verificou-se que países desenvolvidos como a Itália, Espanha e Estados Unidos publicaram maior número de artigos entre os anos de 1992 a 2017. As revistas que mais publicaram artigos foram a Environmental Sciences, seguida pela Soil Science e Engineering Environmental. As áreas de pesquisas mais abordadas foram a Agricultura e a Ecologia das Ciências Ambientais.

Com relação aos macronutrientes, o nitrogênio, fósforo e potássio foram os mais mencionados nos artigos, enquanto outros nutrientes como carbono, cálcio, magnésio, sódio, enxofre, cloro alcançaram menor número de citações em relação ao NPK. Considerando os micronutrientes, os elementos mais citados foram zinco, cobre e chumbo e outras substâncias como cádmio, níquel, cromo, magnésio, ferro, mercúrio, arsênio e cobalto alcançaram menor percentual de citações. Por fim, as culturas mais citadas nos artigos foram o milho, o tomate e o trigo.

A partir dos dados expostos, foi possível observar que os estudos relacionados ao uso da compostagem de resíduos orgânicos para produção adubo cresceu entre as décadas e tem se tornado uma prática de disposição de resíduos cada vez mais adotada entre os países, como forma de preservar o meio ambiente e aumentar a vida útil dos aterros. Além disso, é possível reduzir o volume de fertilizantes sintéticos, uma vez que o composto produzido é rico em 
nutrientes que podem suprir a necessidade das plantas, minimizando assim, a exploração dos recursos naturais.

Neste sentido mostra-se essencial a realização de mais investimentos em estudos e que mostrem de forma clara as vantagens ambientais e sociais de aproveitar a fração orgânica dos resíduos por meio da compostagem. Recomenda-se também melhorar as instalações existentes e aderir uma fiscalização mais rigorosa quanto ao descarte dos resíduos e a adoção de leis estaduais e municipais que incentivem a compostagem. A educação ambiental também pode ser uma ferramenta útil para disseminar a sensibilização na população sobre a importância de seu papel na hora de descartar o lixo de forma adequada.

\section{Referências}

ANDREOLI, C. V; VON SPERLING, M; FERNANDES, F. Lodo de esgoto: tratamento e disposição final. 2. ed. Belo Horizonte: Editora UFMG, 2014. 444 p.

ASSOÇAÇÃO BRASILEIRA DE EMPRESAS DE LIMPEZA PÚBLICA E RESÍDUOS ESPECIAIS (ABRELPE). Panorama dos resíduos sólidos no Brasil. São Paulo, 2016. Disponível em: <http://www.abrelpe.org.br/Panorama/panorama2016.pdf>. Acesso em 15 mar. 2018.

ASSOCIAÇÃO BRASILEIRA DE NORMAS TÉCNICAS (ABNT). NBR 10004 - Resíduos Sólidos: classificação. Rio de Janeiro, 1987.

BARros, J. F. C; CALAdO, J. G. A. Cultura do Milho. Évora: Universidade de Évora, 2005.

BETTIOL, W; CAMARGO, O. A. Lodo de esgoto: impactos ambientais na agricultura. Jaguariúna: Embrapa Meio Ambiente, 2006. 349p.

BRADY, N.C; WEIL, R.R. Elementos da natureza e propriedades dos solos. 3. ed. Porto Alegre: Bookman, 2013. 704p.

BRASIL. Lei $\mathrm{n}^{-}$12.305, de 2 de agosto de 2010. Institui a Política Nacional de Resíduos Sólidos; altera a Lei no ${ }^{-9.605}$, de 12 de fevereiro de 1998; e dá outras providências. Diário Oficial da União, Brasília, DF, 2 ago. 2010. Disponível em: < http://www.planalto.gov.br/ccivil_03/_ato2007-2010/2010/lei/112305.htm>. Acesso em: 12 fev. 2018.

BRASIL. Lei $n^{0}$ 6.938, de 31de agosto de 1981. Dispõe sobre a Política Nacional de Meio Ambiente, seus fins e mecanismos de formulação e aplicação, e dá outras providencias. Diário Oficial da União, Brasília, DF, 31 de ago. 1981. Disponível em: < http://www.planalto.gov.br/ccivil_03/leis/16938.htm>. Acesso em: 14 mar. 2018. 
CASTILHOS JR, A. B. (coord). Gerenciamento de resíduos sólidos urbanos com ênfase na proteção de corpos d'água: prevenção, geração e tratamento de lixiviados de aterros sanitários. Rio de Janeiro: RiMa, ABES, 2006.

CHAPULA, C. A. M. O papel da infometria e da ciênciometria e sua perspectiva nacional e internacional, Brasília, Ciência da Informação, v. 27, n.2, p. 134-140, maio/ago 1998. Disponível em: <http://www.scielo.br/pdf/\%0D/ci/v27n2/macias.pdf>. Acesso em: 15 mar. 2018.

COMISSÃO EUROPEIA. Exemplos de compostagem e de recolhas selectivas bem sucedidas. Luxemburgo: Serviço das Publicações Oficiais das Comunidades Europeias, 2000. 68p. Disponível em: <http://ec.europa.eu/environment/waste/publications/pdf/compost_pt.pdf>. Acesso em: 7 fev. 2018.

COMPROMISSO EMPRESARIAL PARA RECICLAGEM (CEMPRE). Cempre Review 2015. Disponívelem:<file:///C:/Users/usuario/Downloads/o_1abo5n62k1ra0166

COOPER, M; ZANON, A. R; REIA, M. Y; MORATO, R. W. Compostagem e reaproveitamento de resíduos orgânicos agroindustriais: teórico e prático. Piracicaba: ESALQ - Divisão de biblioteca, 2010. 35p.

CORREA, S. M. B. B. Probabilidade e estatística. 2. ed. Belo Horizonte: Universidade Católica de Minas Gerais, Minas Gerais, PUC - Minas Virtual, 2003. 116p.

COSCIONE, A. R; NOGUEIRA, T. A. R; PIRES, A. M. M. Uso agrícola de lodo de esgoto: Avaliação após a Resolução n ${ }^{\circ} 375$ do CONAMA. Botucatu: FEPAF, 2010. 407p.

ERICKSON, B. E., 2002, Analyzing the ignored environmental contaminants. Environmental Science \& Technology, 36: 140A-145A.

FERNANDES, F. Manual prático para a compostagem de biossólidos. Rio de Janeiro; PROSAB; 1999. $84 \mathrm{p}$

FERREIRA, S. S. Análise cienciométrica de estudos visando à recuperação de ambientes aquáticos continentais após a Conferência das Nações Unidas sobre o meio ambiente e desenvolvimento - Rio 92. Trabalho de Conclusão de Curso (Bacharelado em Engenharia Ambiental). Funcesi, Itabira, 2016.

FETTI, G. L. R. Avaliação do efeito da inoculação de fungos termofílicos em pilhas de compostagem de lixo urbano. 2014. 73 f. Tese (Mestrado em Ciências Biológicas) Universidade Estadual Paulista Júlio de Mesquita Filho, São José do Rio Preto. 2014. Disponível em: <https://repositorio.unesp.br/bitstream/handle/11449/110638/000790139.pdf?sequence=1>. Acesso em: 5 fev. 2018

FILGUEIRA, F. A. R. Manual de olericultura: agrotecnologia moderna na produção e comercialização de hortaliças. Viçosa: Editora UFV, 2000. 402 p 
GALEFFI, C. Usina de compostagem na Itália. 2013. Disponível em: < http://www.portalresiduossolidos.com/usina-de-compostagem-de-salerno-na-italia/>. Acesso em: 10 fev. 2018.

GIL, A. C. Como elaborar projetos de pesquisa. 4. ed. São Paulo: Atlas, 2002.

GUIMARÃES, J. C. S. Utilização do lodo de esgoto na agricultura: uma análise cienciométrica. Trabalho de Conclusão de Curso (Bacharelado em Engenharia Ambiental). Funcesi, Itabira, 2017.

INSTITUTO BRASILEIRO DE GEOGRAFIA E ESTATÍSTICA IBGE). Pesquisa Nacional por Amostra de Domicílios (PNAD). 2010.

J1hls1fa019eca.pdf>. Acesso em: 15 mar. 2018

JOURNAL OF ENVIRONMENTAL SCIENCES. Journals. 2018. Disponível em: <https://www.journals.elsevier.com/journal-of-environmental-sciences>. Acesso em: 13 março 2018.

LUDWIG, A. C. W. Fundamentos e pratica metodologia cientifica. 2. ed. Rio de Janeiro: Vozes, 2012.

MARCONI, M. A; LAKATOS, E. M. Fundamentos de metodologia científica. 5. ed. São Paulo: Atlas, 2003.

MASSUKATO, L. M. Compostagem: nada se cria, nada se perde; tudo se transforma. 1. ed. Brasília: IFB, 2016.

MOREIRA. F. M. S; SIQUEIRA, J. O. Microbiologia e bioquímica do solo. 2. ed. atualizada e ampliada. Lavras: Editora UFLA, 2006. 729p.

MORESI, E.A.D. Apostila de metodologia da pesquisa. Brasília: Universidade Católica de Brasília, 2003.

OLIVEIRA, A. M. G.; AQUINO, A. M. de; CASTRO NETO, M. T. Compostagem caseira de lixo orgânico doméstico. Cruz das Almas, BA: Ministério da Agricultura, Pecuária e Abastecimento, 2005. Disponível em: < https://ainfo.cnptia.embrapa.br/digital/bitstream/item/128239/1/Compostagem-caseira-delixo-organico-domestico.pdf>. Acesso em: 01 abril 2018.

PARLAMENTO EUROPEU. Gestão de resíduos urbanos: objetivos mais ambiciosos para uma economia circular. Disponível em: http://www.europarl.europa.eu/news/pt/headlines/society/20170120STO59356/gestao-deresiduos-urbanos-objetivos-mais-ambiciosos-para-uma-economia-circular>. Acesso em 14 mar. 2018.

PEREIRA NETO, J. T. Manual de compostagem: processo de baixo custo. Ed. rev. e aum. Viçosa, MG: Ed. UFV, 2007. 81p.

PHILIPPI JR, A. Saneamento, saúde e ambiente: fundamentos para um desenvolvimento sustentável. Barueri, SP: Manole, 2005. 
PHILIPPI JR, A.; ROMÉRO, M. A.; BRUNA, G. C. Curso de gestão ambiental. 2. ed. atual. e ampl., Manole: Barueri, 2014.

REVISTA AMBIENTE PARA OS EUROPEUS. Elevar a fasquia da reciclagem. 2014. Disponível em: < https://ec.europa.eu/environment/efe/themes/raising-bar-recycling_pt>. Acesso em 14 mar. 2018.

REVISTA DAE. 15 $^{\circ}$ Encontro técnico de alto nível: compostagem em escala industrial. Disponível em: <http://revistadae.com.br/site/evento/2487-15o.-Encontro-Tecnico-de-AltoNivel-Compostagem-em-Escala-Industrial>. Acesso em: 15 fev. 2018.

RODRIGUES, J. S. Presença de fármacos e hormônios na água: uma análise cienciométrica. Trabalho de Conclusão de Curso (Bacharelado em Engenharia Ambiental). Funcesi, Itabira, 2017.

SAIANI, C. C. S; DOURADO, J; TONETO JÚNIOR, R. Resíduos sólidos no Brasil: oportunidades e desafios da lei federal $\mathrm{n}^{\circ} 12.305$ (lei de resíduos sólidos). Barueri, SP: Minha Editora, 2014.

SILVA, J. B. C; GIORDANO, L. B; FURUMOTO, O; BOITEUX, L. S; FRANÇA, F. H; BÔAS, G. L. V; BRANCO, M. C; MEDEIROS, M. A; MAROUELLI, W; SILVA, W. L. C; LOPES, C. A; NASCIMENTO, W. M; PEREIRA, W. Cultivo de Tomate para Industrialização. Embrapa Hortaliças Sistemas de Produção, 1-2 ${ }^{\mathrm{a}}$ ed. Versão eletrônica, dez/2006.

Disponível

em: <https://sistemasdeproducao.cnptia.embrapa.br/FontesHTML/Tomate/TomateIndustrial_2ed/ composicao.htm>. Acesso em: 14 março 2018.

SILVA, P. B. S. A restauração ecológica no Brasil entre os anos de 1992 e 2016: um estudo cienciométrico. Trabalho de Conclusão de Curso (Bacharelado em Engenharia Ambiental). Funcesi, Itabira, 2016.

SOUZA, J. L. de. Sistema orgânico de produção de tomate. In: INSTITUTO CAPIXABA DE PESQUISA, ASSISTENCIA TÉCNICA E EXTENSÃO RURAL. Tomate. 2010. Vitória, ES: Incaper, p. 35 - 67. ISBN 978-85-89724-17-3. Disponível em:<https://www.researchgate.net/publication/267232473_Sistema_Organico_de_Producao_ de_Tomate>. Acesso em: 14 Mar. 2018.

TSUTIYA, M. T; COMPARINI, J. B.; SOBRINHO, P. A; HESPANHOL, I; MELO, J.

MARQUES, M. O. Biossólidos na agricultura. 2. ed. São Paulo: ABES, 2002. 468p.

UNIÃO EUROPEIA. Regulation (EC) n 178/2002 of the European Parliament and of the Council of 28 January 2002. Laying down the general principles and requirements of food law, establishing the European Food Safety Authority and laying down procedures in matters of food safety. Disponível em: <http://eurlex.europa.eu/LexUriServ/LexUriServ.do?uri=OJ:L:2002:031:0001:0024:en:PDF>. Acesso em: 15 jan. 2018.

VERGARA, S. C. Projetos e relatórios de pesquisa em administração. 13. ed. São Paulo: Atlas, 2011. 
Research, Society and Development, v. 7, n. X, p. 01-X, eXX, 2018 ISSN 2525-3409 (CC BY 4.0) 